\section{SOIL SCIENCE}

\section{Identification of Methyl Nitrite in the Reaction Product of Nitrous Acid and Lignin}

IN a recent communication, Stevenson and Swaby ${ }^{1}$ reported the presence of a heretofore unobserved nitrogenous gas in the product obtained by reacting nitrous acid with lignins. The identity of the gas was not established; the compounds eliminated as possibilities included nitric oxide, nitrogen dioxide, nitrogen peroxide, dinitrogen tetraoxide, nitrogen pentoxide, nitromethane, and hydrogen nitrate.

We have now established the identity of the unknown gas. A preliminary investigation showed that the gas contained carbon; for example, carbon dioxide was liberated by oxidation with permanganate, and carbon monoxide was produced by thermal decomposition. The evidence indicated that the gas was methyl nitrite $\left(\mathrm{CH}_{3}-\mathrm{O}-\mathrm{N}=\mathrm{O}\right)$. Inspection of the infra-red spectra of the unknown ${ }^{\mathrm{t}}$ shows that two bands are present at frequencies of about $1,685 \mathrm{~cm}^{-1}$ and $1,625 \mathrm{~cm}^{-1}$; these are characteristic of the $\mathrm{N}=\mathrm{O}$ stretching vibrations (transand cis-forms) of nitrites ${ }^{2}$.

Positive confirmation that the unknown gas is methyl nitrite was obtained by comparison with a known sample of methyl nitrite. To obtain the reference gas, $10 \mathrm{ml}$. of a 2 per cent $(\mathrm{v} / \mathrm{v})$ solution of methyl alcohol in $0.3 \mathrm{~N}$ sulphuric acid was added to the reaction chamber of a Van Slyke manometric apparatus, followed by $1 \mathrm{ml}$. of an 80 per cent $(\mathrm{w} / \mathrm{v})$ solution of sodium nitrite. The methyl nitrite thus produced was separated from nitric oxide (formed by self-degradation of nitrous acid) by absorption of the latter in an $\mathrm{Na}_{2} \mathrm{HPO}_{4}-\mathrm{KMnO}_{4}-\mathrm{NaNO}_{3}$ solution. The unknown gas was obtained by reacting nitrous acid with 'Meadol MRM' lignin, using the procedure described earlier ${ }^{1}$. The analytical procedures used for the comparisons included gas chromatography, infra-red spectrophotometry, and manometry.

Without exception, the gas obtained from lignin behaved similarly to the prepared sample of methyl nitrite. Some of the more pertinent observations are listed here:

(1) Both gases were absorbed slowly by the $\mathrm{Na}_{2} \mathrm{HPO}_{4}$ $\mathrm{KMnO}_{4}-\mathrm{NaNO}_{3}$ solution used to remove nitric oxide from the nitrous acid reaction mixture, and, in each case, trace amounts of carbon dioxide and nitrous oxide were detected in the residual gases.

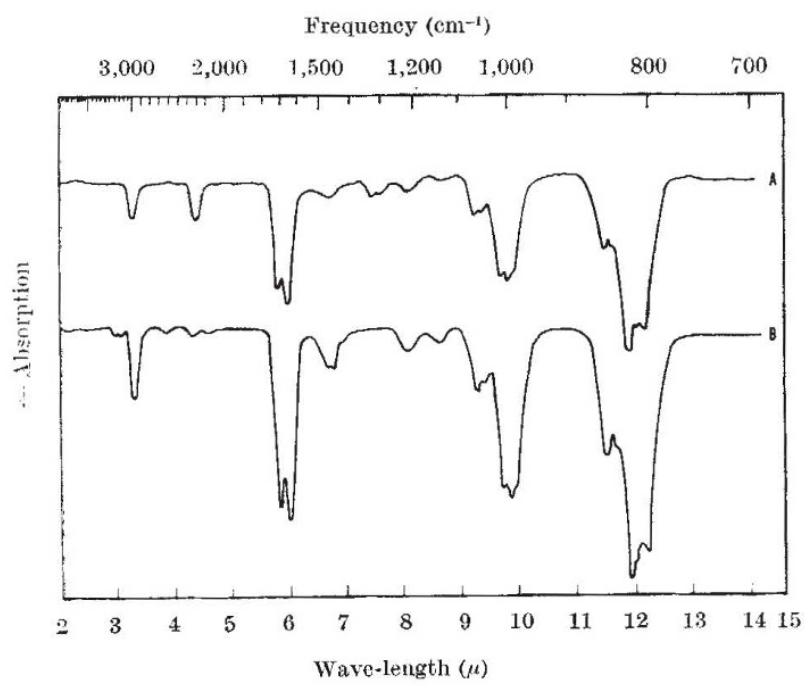

Fig. 1. Infra-red absorption spectra of: (A) gaseous product obtainet l,y reacting nitrous acid with lignin; and $(B)$ methyl nitrite. Th spectrum of the gas obtained from lignin also shows the presence Ditrous oxide. Nitric oxide her in permanganate solution
(2) Thermal degradation $\left(T>100^{\circ} \mathrm{C}\right)$ of both gases resulted in the production of equimolar amounts of nitric oxide. In addition, trace amounts of carbon monoxide were produced.

(3) Both gases were capable of being reduced with aqueous sulphite, and acidification of the resulting mixture resulted in the production of considerable quantities of nitrous oxide.

(4) The infra-red absorption patterns of the two gases were identical (Fig. 1), and they were very similar to the spectra Tarte ${ }^{3,4}$ reported for methyl nitrite.

Thus, it is evident that the hitherto unknown gas is methyl nitrite.

We thank Prof. W. Lüttke, University of Göttingen, for providing information on published infra-red patterns of methyl nitrite.

F. J. Stevenson

M. A. KIRKMAN

Department of Agronomy,

University of Illinois,

$$
\text { Urbana. }
$$

'Stevenson, F. J., and Swaby, R. J., Nature, 199, 97 (1962).

Bellamy, L. J., The Infra-red Spectra of Complex Molecules (Methuen ant Co., Ltd., London, 1959).

${ }^{3}$ Tarte, P., Bull. Soc. Chim. Belg., 60, 227 (1951).

' Tarte, P., J. Chem. Phys., 20, 1570 (1952).

\section{Role of Iron Oxides in the Bonding of Soil Particles}

THE presence of significant amounts of iron oxides in soils is generally considered to exert important effects on their physical properties, but no satisfactory experimental evidence exists to substantiate this view. A series of experiments has therefore been carried out to determine what effect the removal of jron oxides from natural aggregates has on their stability. In addition attempts have been made to improve the aggregation of soils by precipitation of iron and aluminium oxides on the soil particles.

Air-dry aggregates $1 \cdot 0-2.0 \mathrm{~mm}$ in size from samples of Buchanan's laterite from Kerala, Southern India, a Krasnozem from northern New South Wales, various Rendzinas, Terra Rossas and Red Brown Earths from South Australia and a Lateritic Red Earth from Katherine. North Australia, were separated by sieving. 'The aggregates were wet successively at $100 \mathrm{~cm}$ and $8 \mathrm{~cm}$ suction before they were immersed in water. They were then treated with $0.3 \mathrm{M}$ sodium dithionite either alone or with sodium citrate and sodium bicarbonate to remove free iron oxides ${ }^{1}$. The stabilities of the treated aggregates were compared with those of controls, which had received the same reagents except that dithionite was replaced by sodium sulphate. The effect of the treatment on aggregate stability was measured by the change in permeability of a bed of the sodium saturated aggregates to $0.05 \mathrm{~N}$ sodium chloride ${ }^{2}$ and also by wet sieving.

All these soils contained relatively large amounts of iron oxides (2-15 per cent), but for none of them did the stability of the dithionite-treated sample fall below that of the corresponding sample treated with the control reagents. Particle size analyses were also carried out. Organic matter was first destroyed by peroxidation, and the soils were then treated with sodium dithionite and the citratebicarbonate buffer or sodium sulphate and buffer. The dithionite treatment failed to increase the proportions of clay or silt above those of the control treatments. In fact, when the results were expressed on the basis of original weight of untreated soil, decreases in the proportion of clay were observed corresponding approximately to the amount of iron oxide removed.

These results showed that in the soils studied the stability of the macro-aggregates was not dependent on the 